\title{
PROPOSTA DE EDUCAÇÃO AMBIENTAL NO PARQUE ESTADUAL SÍTIO FUNDÃO (CRATO/CE) COM ÊNFASE NA FLORA NATIVA
}

\author{
Priscilla Augusta de Sousa Fernandes ${ }^{1}$ \\ Rosimeire Soares Vieira ${ }^{2}$ \\ Mayra Alves Pinheiro ${ }^{3}$ \\ Marcelo Martins de Moura-Fé 4
}

Resumo: As Unidades de Conservação da Natureza (UCs) se apresentam como espaços vocacionados para a realização de diversas atividades relacionadas à Educação Ambiental (EA). Nesse contexto, por um lado, as trilhas se notabilizam por não apresentarem, de maneira geral, a necessidade de grandes investimentos, e, por outro lado, por proporcionarem a proximidade entre as pessoas e seus elementos naturais. Sendo assim, este trabalho propõe a sinalização e inclusão de uma nova trilha no roteiro de visitação do Parque Sítio Fundão, na cidade do Crato, região sul do Ceará, com ênfase na flora nativa para utilização como ferramenta de Educação Ambiental e conservação da natureza, sendo desenvolvido nas seguintes etapas: gabinete, campo e laboratório. Na proposta foram selecionadas as seguintes espécies nativas: jatobá, angico, timbaúba e sabiá (Fabaceae), tingui (Sapindaceae), juazeiro (Rhamnaceae) e o mandacaru (Cactaceae). A proposta de melhoria e sinalização da trilha secundária da UC, só vem a contribuir para tal, bem como servir de ferramenta para disseminar novas formas de Educação Ambiental nesta UC, ampliando e divulgando assim os recursos naturais, culturais e históricos, além de servir de vínculo para mudanças de comportamentos, hábitos e atitudes dos visitantes.

Palavras-chave: Biodiversidade; GeoPark Araripe; Patrimônio Natural; Trilha; Unidade de Conservação.

\footnotetext{
${ }^{1}$ Graduada em Ciências Biológicas pela Universidade Regional do Cariri - URCA.

E-mail: prisciasf@gmail.com

2 Graduanda em Ciências Biológicas pela Universidade Regional do Cariri - URCA.

E-mail: rosimeiresv2009@hotmail.com

${ }^{3}$ Graduada em Geografia pela Universidade Regional do Cariri - URCA. E-mail: mayra.acops@hotmail.com

${ }^{4}$ Geógrafo. Doutor em Geografia (PPGG-UFC). Professor do Departamento de Geociências da

Universidade Regional do Cariri (DEGEO-URCA). E-mail: marcelo.mourafe@urca.br
} 


\section{Introdução}

A Educação Ambiental (EA) deve estar presente em todos os espaços de convivência e, principalmente, naqueles que propõe contribuir para a educação das cidadãs e dos cidadãos, assim, além das escolas, ela pode ser feita nas universidades, em cursos profissionalizantes, nas nossas ruas e casas, associações de bairro, locais de trabalho, sindicatos, comunidades religiosas, bem como em locais de lazer como clubes e entidades recreativas, praças, praias, parques, reservas ecológicas (MELO, 2007), nas unidades de conservação e nos geossítios também.

O imóvel Sítio Fundão foi transformado em uma Unidade de Conservação (UC) de Proteção Integral pelo Governo do Estado de Ceará, através do Decreto no 29.307, de 05 de junho de 2008, com base no reconhecimento de que a área apresentava condições para a criação de um Parque Estadual, pois apresentava riqueza de patrimônio natural (biodiversidade e geodiversidade), histórico-cultural (edificações) de relevante importância para o município do Crato e do estado do Ceará.

Composto por corpos d'água, além de atender as finalidades ambientais e culturais de preservação de recursos naturais, históricos e, ainda, por exibir atributos de beleza exuberante, o Parque Estadual (PARES) Sítio Fundão abrange parte do Geossítio Batateiras, sítio natural do GeoPark Araripe.

O GeoPark Araripe, o primeiro geoparque do continente americano, foi criado em 2006 e cobre uma área atual de aproximadamente $3.796 \mathrm{~km}^{2}$. De maneira geral, os geoparques são territórios dotados de importante patrimônio geológico, sendo promovidos pela UNESCO, mas não objetiva ser um simples espaço natural sem presença humana, mas sim, um território de interação, de encontro da sociedade, da natureza e do tempo (CEARÁ, 2012).

De acordo com Macêdo e Pinheiro (2014), o processo de implantação de um geoparque estabelece relações com o geoturismo e a geoeducação, que são formas de geoconservação (MOURA-FÉ, 2016). O geoturismo está relacionado com o ecoturismo, porém mais voltado para o ambiente físico e abiótico, tem o patrimônio geológico como seu principal atrativo e busca sua proteção e divulgação das suas áreas naturais (MOREIRA, 2010; LOBO et al., 2012).

Por sua vez, a geoeducação desenvolve atividades de educação voltadas a conscientização, valorização e preservação dos espaços naturais e suas belezas cênicas, além de servir para a expansão do geoturismo e da geoconservação, compondo assim o tripé de sustentação dos geoparques (OLIVEIRA, 2014).

Considerando a importância da geodiversidade e a ampla possibilidade de inserção social da Educação Ambiental, Moura-Fé et al. (2016) propõem o estabelecimento e o desenvolvimento do conceito científico da geoeducação, como a segunda estratégia geoconservacionista, sendo entendida como um ramo específico da Educação Ambiental a ser aplicado na geoconservação e 
que seja tratado, fomentado e desenvolvido nos âmbitos formais e/ou não formais do ensino.

No GeoPark Araripe existem nove geossítios abertos para visitação, sendo eles: Colina do Horto, Cachoeira de Missão Velha, Floresta Petrificada do Cariri, Batateiras, Pedra Cariri, Parque dos Pterossauros, Riacho do Meio, Ponte de Pedra e Pontal da Santa Cruz (CORDEIRO, MACEDO e BASTOS, 2015), e de acordo com Silveira et al. (2012) compreende os territórios dos seguintes municípios: Crato, Juazeiro do Norte, Barbalha, Nova Olinda, Santana do Cariri e Missão Velha (Figura 1).

De forma específica, o geossítio Batateiras se localiza no sopé da Chapada do Araripe, caracterizado pela presença de fontes naturais de água, pela cascata do Lameiro e importantes edificações históricas, como a primeira usina hidroelétrica da cidade do Crato e o Sítio Fundão que, por anos, serviu como estação ecológica através do trabalho do sr. Jefferson Alencar, seu antigo proprietário (CEARÁ, 2012).

Desde sua criação, o Pares Sítio Fundão tem recebido visitas de escolas e universidades, turistas e moradores locais, sendo administrado pela Secretaria de Meio Ambiente do Estado do Ceará (SEMA), com agendamento prévio para obtenção de autorização para cada visita, as quais são feitas de acordo com normas e restrições da administração, incluindo ainda, caso solicitado, o acompanhamento de um monitor.

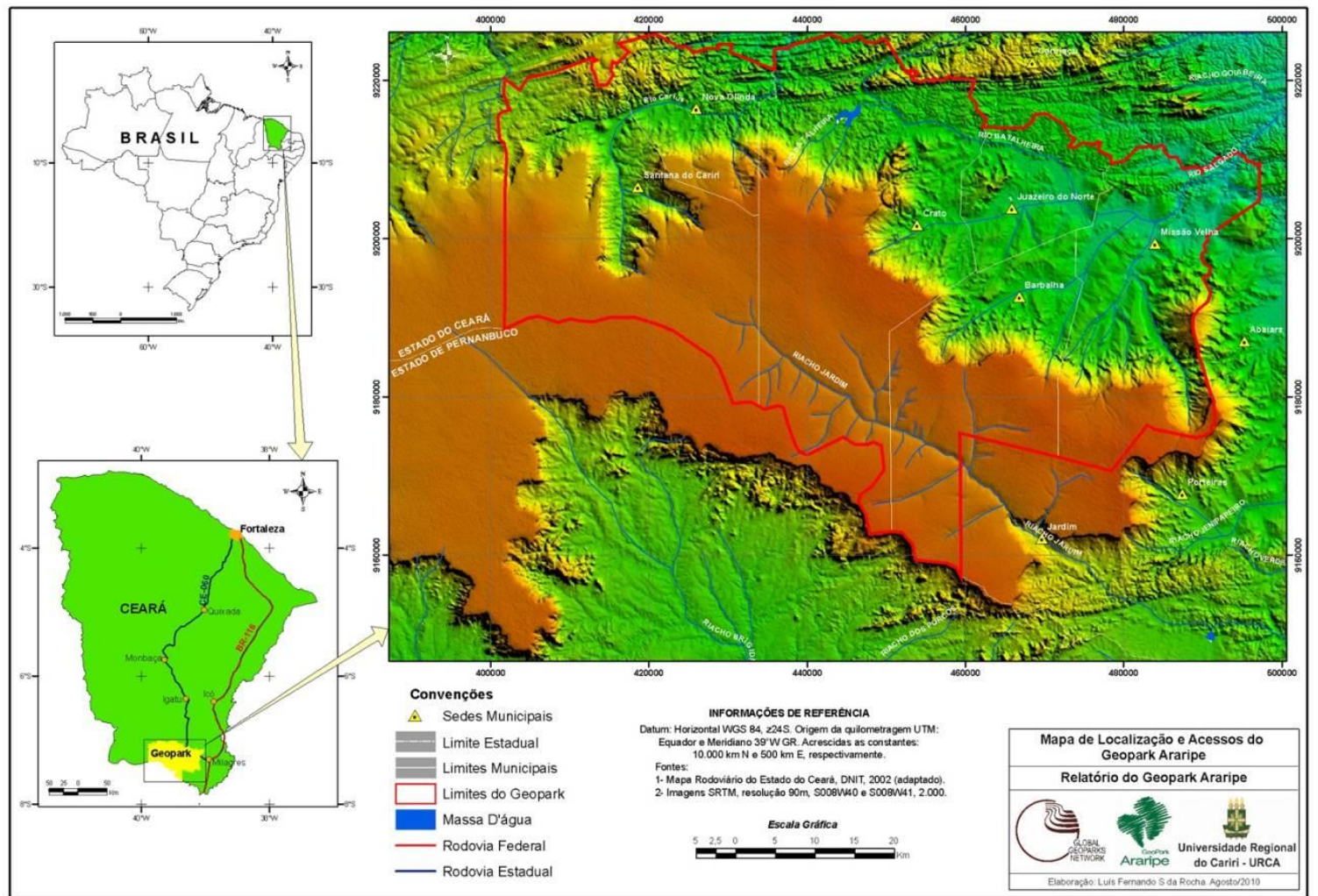

Figura 1: Mapa de localização do GeoPark Araripe. Fonte: Ceará (2012). 
As visitas são feitas através da trilha principal e tem como atração a Casa de Taipa que pertenceu ao sr. Jefferson e o geossítio Batateiras. Contudo, o Pares Sítio Fundão apresenta potencial de crescimento em relação às suas atratividades. Dentre elas, está uma trilha existente e, ainda, sem uso definido.

As trilhas interpretativas são definidas como percurso preestabelecido, onde são apresentados ao visitante, de forma guiada ou não, vários elementos daquele ambiente, ligados a um tema interpretativo bem definido (PROJETO DOCES MATAS, 2002). Como observado por Lima-Guimarães (2010), essas trilhas colaboram de modo positivo e efetivo para o desenvolvimento de ações conservacionistas.

Diante do exposto, este trabalho tem como objetivo principal, propor a utilização de uma trilha já existente, mas não utilizada no roteiro de visitação, através da sua sinalização, identificando aspectos relevantes da biodiversidade local, a serem utilizados como ferramenta de Educação Ambiental, visando contribuir efetivamente e potencializar a conservação da natureza no Parque Estadual Sítio Fundão.

\section{Metodologia}

\section{Área de Estudo}

O Parque Estadual Sítio Fundão (Figura 2) está localizado a $3 \mathrm{~km}$ do centro da cidade do Crato, tem uma área correspondente a 93,5 ha, onde são encontrados diversos tipos vegetacionais como cerrado, caatinga arbórea e arbustiva e mata ciliar circundando o rio Batateiras (MORAIS et al., 2009), além de resquícios de mata atlântica e ainda formações geológicas que fazem parte do geossítio Batateiras do GeoPark Araripe (JUSTO; RODRIGUES, 2014).
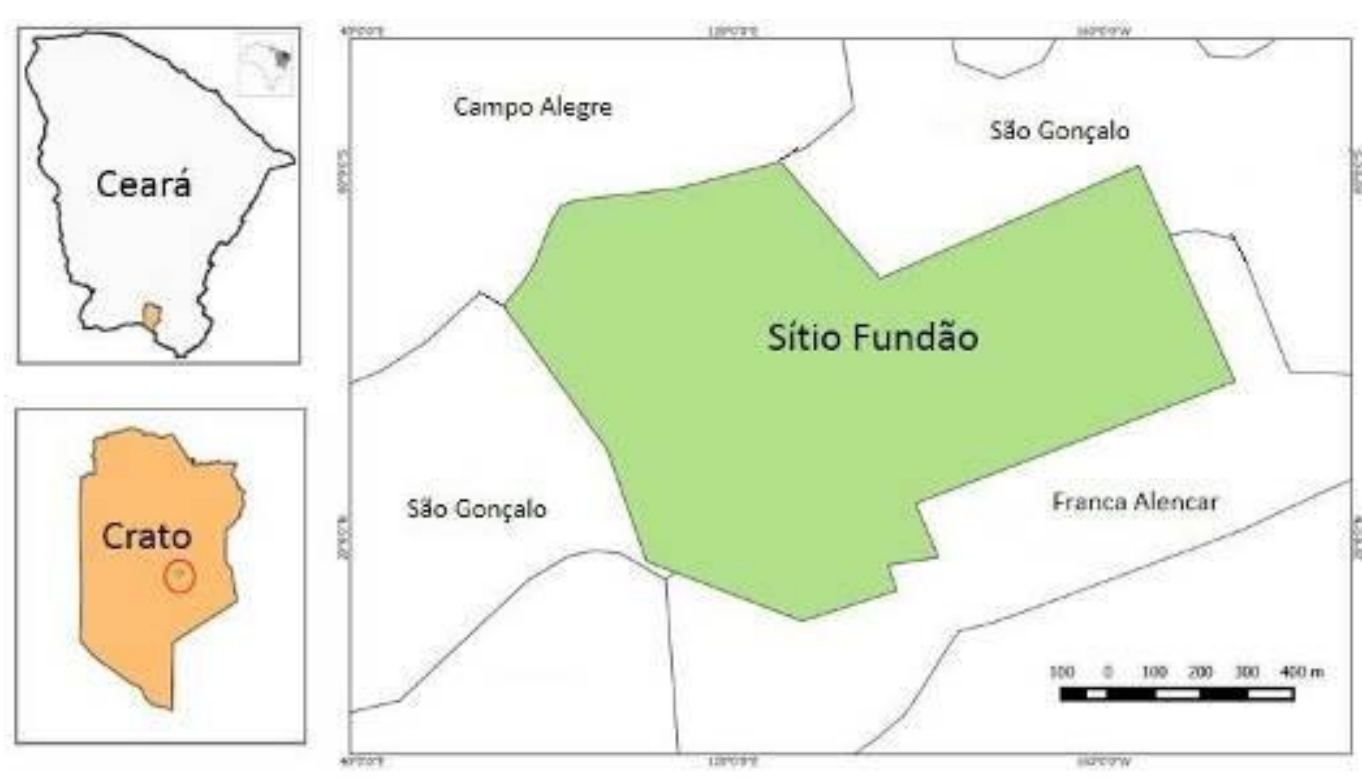

Figura 2: Localização do Parque Estadual Sítio Fundão. In: FERNANDES et al. (2016). 
Além das trilhas ecológicas, o parque tem como atrativo a existência de uma casa feita de taipa, edificação de barro batido e madeira, comum no Nordeste, com um primeiro andar, sendo a única casa do Brasil registrada neste modelo de construção, e que foi recentemente transformado em um Centro de Visitação. A UC também possui ruínas de um engenho de cana-deaçúcar construído por volta de 1880.

\section{Levantamentos}

A metodologia foi compartimentada em etapas de gabinete, campo e laboratório. A etapa de gabinete foi desenvolvida parcialmente no escritório da Secretaria Estadual do Meio Ambiente (SEMA-CE) e no Laboratório de Geomorfologia e Pedologia (GeoPed) da Universidade Regional do Cariri (URCA), onde foram feitos os planejamentos da pesquisa, além de criteriosos levantamentos bibliográfico e cartográfico pertinentes a área de estudo e à temática da Educação Ambiental (EA) em UCs.

Em relação à etapa de campo, os levantamentos realizados diretamente no Pares Sítio Fundão, com ênfase na trilha ainda não utilizada, tiveram a finalidade de identificar elementos relevantes da biodiversidade da região, com foco na flora nativa, identificada apenas por nome popular e da família, pois no período do desenvolvimento deste estudo os espécimes não apresentavam material fértil para devida coleta e identificação a nível de espécie.

Por fim, a cartografação dos resultados do trabalho de pesquisa, tanto de gabinete quanto de campo, foi realizada no Laboratório de Geoprocessamento (LabGeo) da URCA. Nesta etapa foram utilizados os softwares QGis 2.10 e Google Earth PRO para confecção dos mapas apresentados aqui.

\section{Resultados e discussão}

Pellin et al., (2014) consideram a gestão de áreas protegidas no Brasil como imenso desafio, que tende a aumentar quando estas áreas estão localizadas em ambientes urbanos, como ocorre com a UC em questão, sendo necessário o enfrentamento deste desafio; e ainda pontuam que estas áreas podem ser instrumento importante de sensibilização de grupos sociais e (re)conexão da sociedade urbana com a natureza desde que ofereçam oportunidades de recreação em contato com a natureza e de Educação Ambiental.

Nesse contexto, a administração do Pares Sítio Fundão já apresenta uma série de atividades de Educação Ambiental que já vêm sendo desenvolvidas.

Durante as visitas guiadas pelo monitores da Sema com os estudantes de escolas no Pares Sítio Fundão são realizadas práticas de Educação Ambiental como, por exemplo, o plantio de mudas de plantas nativas pelas crianças, com auxílio de funcionários do parque, incentivando 0 
reflorestamento, recuperação de áreas degradas e contribuindo para o manejo e conservação da flora local, além de frisar a importância da preservação e conservação da natureza através do contato direto das crianças com o meio. Para os estudantes de ensino superior, por sua vez, o roteiro irá depender do propósito da aula, quando ocorre visita guiada, são apresentados os aspectos naturais e histórico-culturais, assim como para os turistas.

Atualmente, nas visitas guiadas, vem sendo apresentado o circuito das árvores, que se localiza na estrada de acesso ao sobrado de taipa, principal trilha da UC, onde no caminho há algumas placas identificando espécies da flora nativa (Figura 3), com a apresentação aos visitantes de informações sobre as espécies como nome popular e científico, aspectos fenológicos, importância econômica, ambiental e medicinal.

O Pares Sítio Fundão também disponibiliza seu espaço para a população circundante praticar exercícios no início da manhã e o no fim da tarde, sendo permitido o acesso a estrada principal, não necessitando de acompanhamento de guia.

Todavia, vale ressaltar, há possibilidades concretas de ampliação da visitação, sobretudo, através da trilha secundária e que apresenta boas condições de uso, mas que ainda não está agregada ao roteiro de visitação, e ao longo desta trilha se deu a ênfase do trabalho de pesquisa.

Sendo assim, nos levantamentos de campo foi percorrida essa trilha, que já havia sido aberta previamente à criação da UC, a fim de reconhecer a área e observar aspectos relevantes. A entrada da trilha (Figura 4) fica a $330 \mathrm{~m}$ da entrada do parque, necessitando de placa de sinalização para a entrada, possui uma extensão de aproximadamente $1,1 \mathrm{~km}$ e se inicia com cota de elevação de $530 \mathrm{~m}$, finaliza com $489 \mathrm{~m}$, sendo que o seu ponto mais baixo está em 479 m (Figura 5).

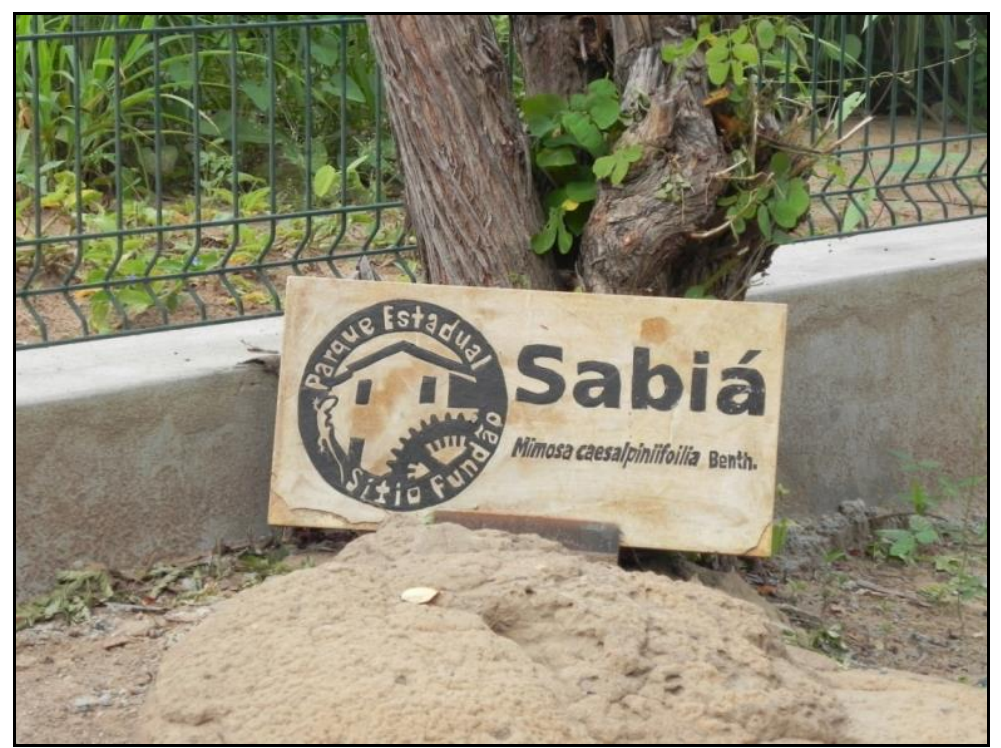

Figura 3: Placa de identificação de espécies na trilha principal do Pares Sítio Fundão. Foto: Marcelo Moura-Fé (Abr/2016). 


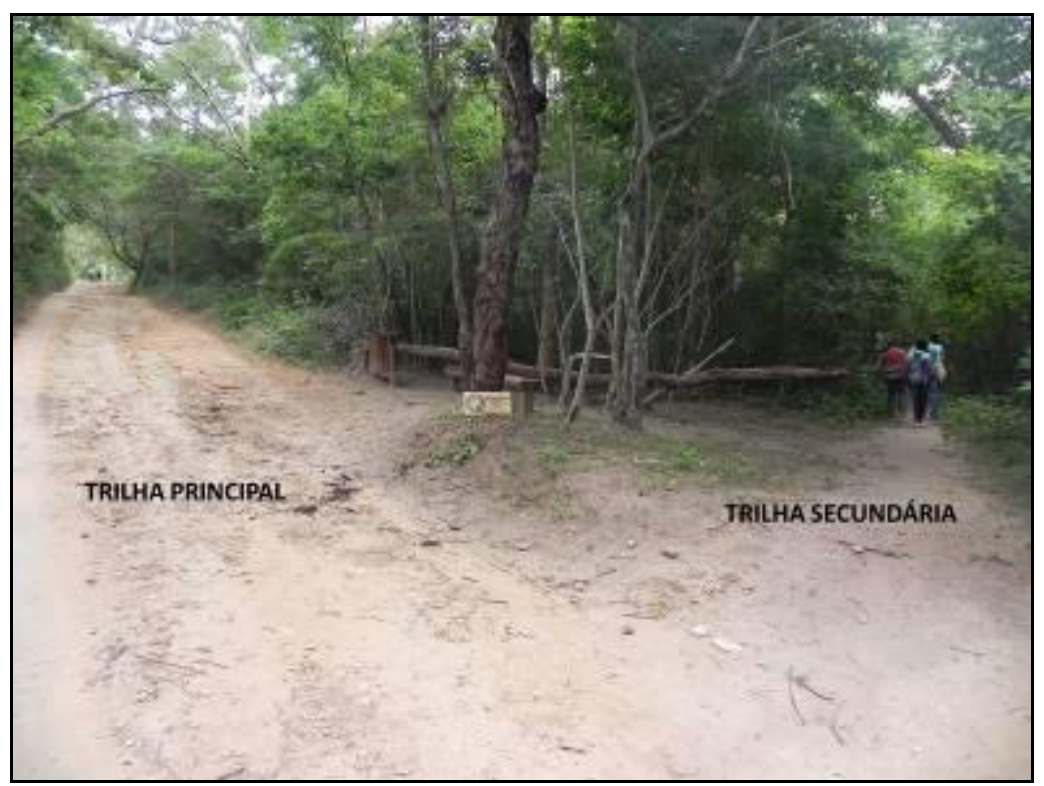

Figura 4: Bifurcação das trilhas no Pares Sítio Fundão. Foto: Marcelo Moura-Fé (Abr/2016).

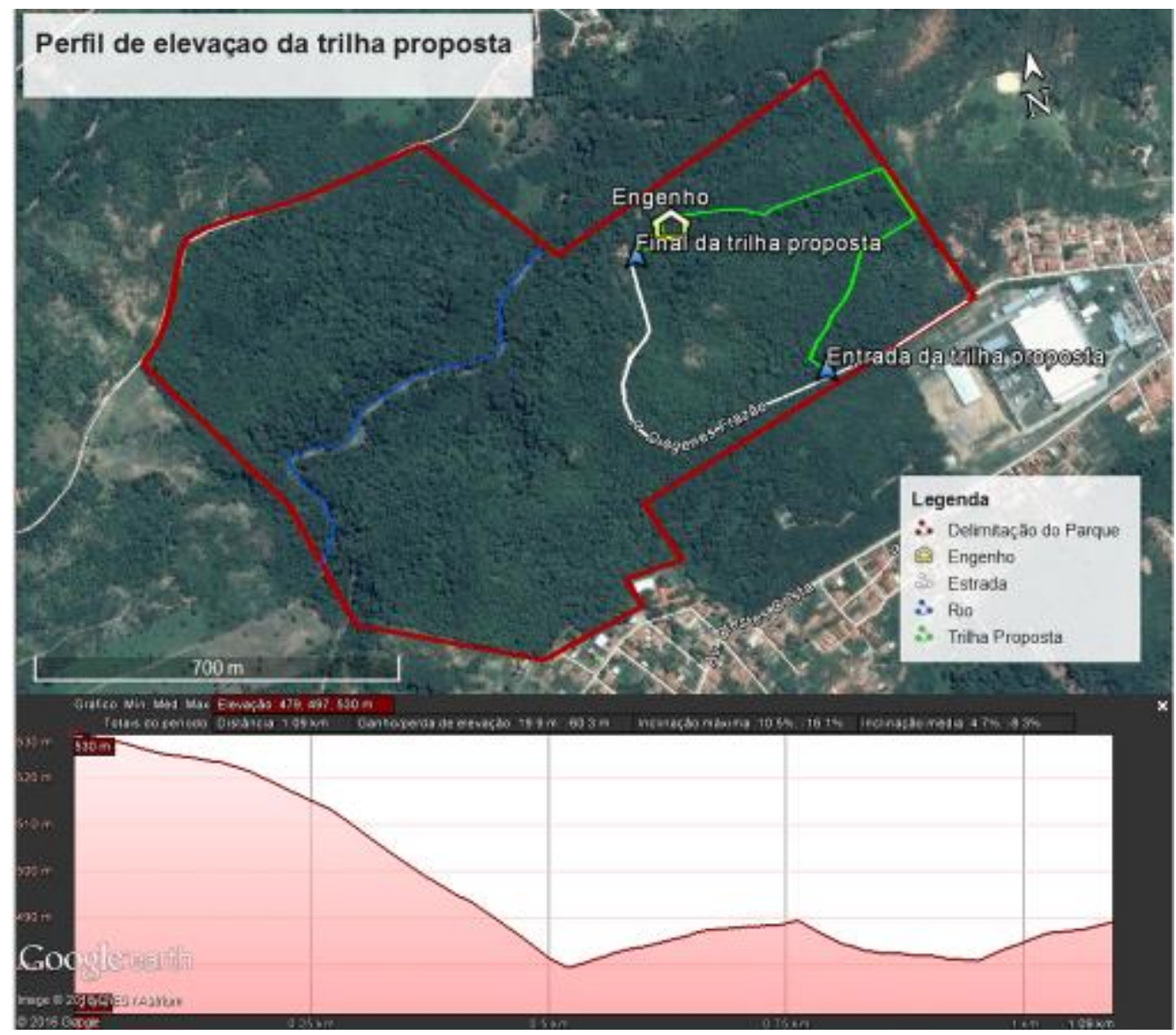

Figura 5: Perfil de elevação da trilha proposta. In: FERNANDES, 2016. No prelo.

Revbea, São Paulo, V. 12, № 4: 207-218, 2017.

revista brasileira educação ambiental 
A sinalização de trilhas em UCs, de acordo com Pietrochinski e Silva (2008), é de fundamental importância para manter o equilíbrio do ecoturismo, pois contribui com a Educação Ambiental, gerando sensibilização dos visitantes, alertando-os aos cuidados necessários ao visitar uma área natural protegida.

Das trilhas abertas no interior do parque, apenas uma está devidamente sinalizada (FERNANDES et al., 2016), daí vem a necessidade da sinalização de outras trilhas, como forma para ampliar as áreas de acesso do visitante, podendo fomentar as ações de Educação Ambiental nesses trajetos, com abordagem da rica biodiversidade da área, tendo em vista que atualmente a maior parte de visitantes do PARES são estudantes.

Moura-Fé (2015) afirma que é importante que a divulgação e sensibilização se dê por este público que está mais aberto a estas iniciativas e com capacidade mais acentuada de interiorização de mensagens de caráter ambiental. Pellin et al. (2014) ressaltam que pessoas que estabelecem contato com as áreas protegidas assimilam a importância e os benefícios da sua existência, tornando-se capazes de defender não só as áreas de seu convívio, mas também as que nem chegarão a conhecer. $E$ as trilhas interpretativas tem importante papel na reintegração biológica, psicológica e cultural dos seres humanos com a paisagem, sendo a paisagem um importante fio condutor nos programas de Educação Ambiental (LIMA-GUIMARÃES, 2010).

Para Pinheiro et al. (2016) as unidades de conservação são espaços amplamente indicados e vocacionados para implantação e desenvolvimento da Educação Ambiental. A sinalização da trilha juntamente com a identificação de espécies que ocorrem nela, podem vir a contribuir para o planejamento e implementação de ações educativas voltadas à conservação dos recursos naturais que, segundo Costa e Costa (2014) corresponde a primeira etapa para implantação de programas de Educação Ambiental.

Vale ressaltar os elementos básicos e norteadores da EA que devem permear as ações, conforme Dias (2004, p. 523):

- Enfoque orientado à solução de problemas concretos da comunidade;

- Enfoque interdisciplinar;

- Participação da Comunidade;

- Caráter permanente, orientado para o futuro.

Além de possibilitar o contato das pessoas com a natureza mostrando a relação dos meios bióticos e abióticos, as trilhas também propõem a transmissão de conhecimentos, bem como a realização de atividades e programas de educação ao ar livre, pois são de suma importância para a prática de Educação Ambiental (ARAÚJO; FARIAS, 2003; COSTA; SILVA; MENESES, 2013). Assim como é considerada uma etapa importante do aprendizado, pois os alunos verão in loco o que foi explanado em sala de aula aumentando seu interesse e compreensão (COLMAN; VAN DAL; SILVA, 2016). 
Neste sentido e com o intuito de identificar elementos da flora nativa que deveriam ser sinalizados, os trabalhos de campo tiveram foco na observação e análise da vegetação, onde foram identificadas várias espécies, dentre as quais foram selecionadas 7 que mais ocorrem na trilha, distribuídas nas famílias Fabaceae, Sapindaceae, Rhamnaceae e Cactaceae.

Inicialmente foram identificadas pelo nome popular, jatobá, angico, timbaúba e sabiá (Fabaceae), tingui (Sapindaceae), juazeiro (Rhamnaceae) e o mandacaru (Cactaceae) (Figura 6) e georreferenciadas (Figura 7), o que facilita o trabalho de sinalização.

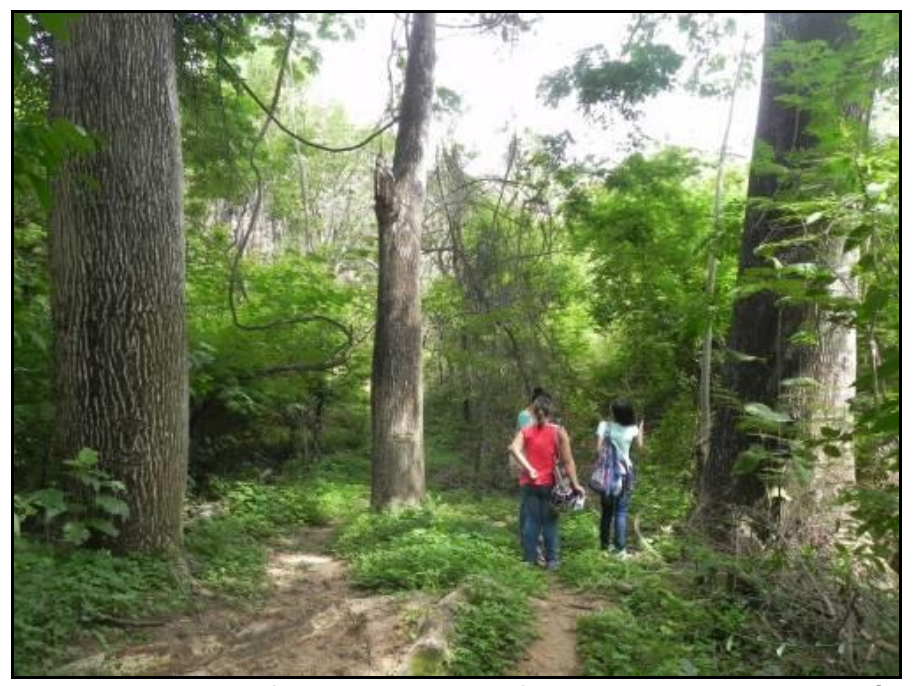

Figura 6: Trabalho de identificação e georreferenciamento das espécies nativas.

Foto: Marcelo Moura-Fé (Abr/2016).

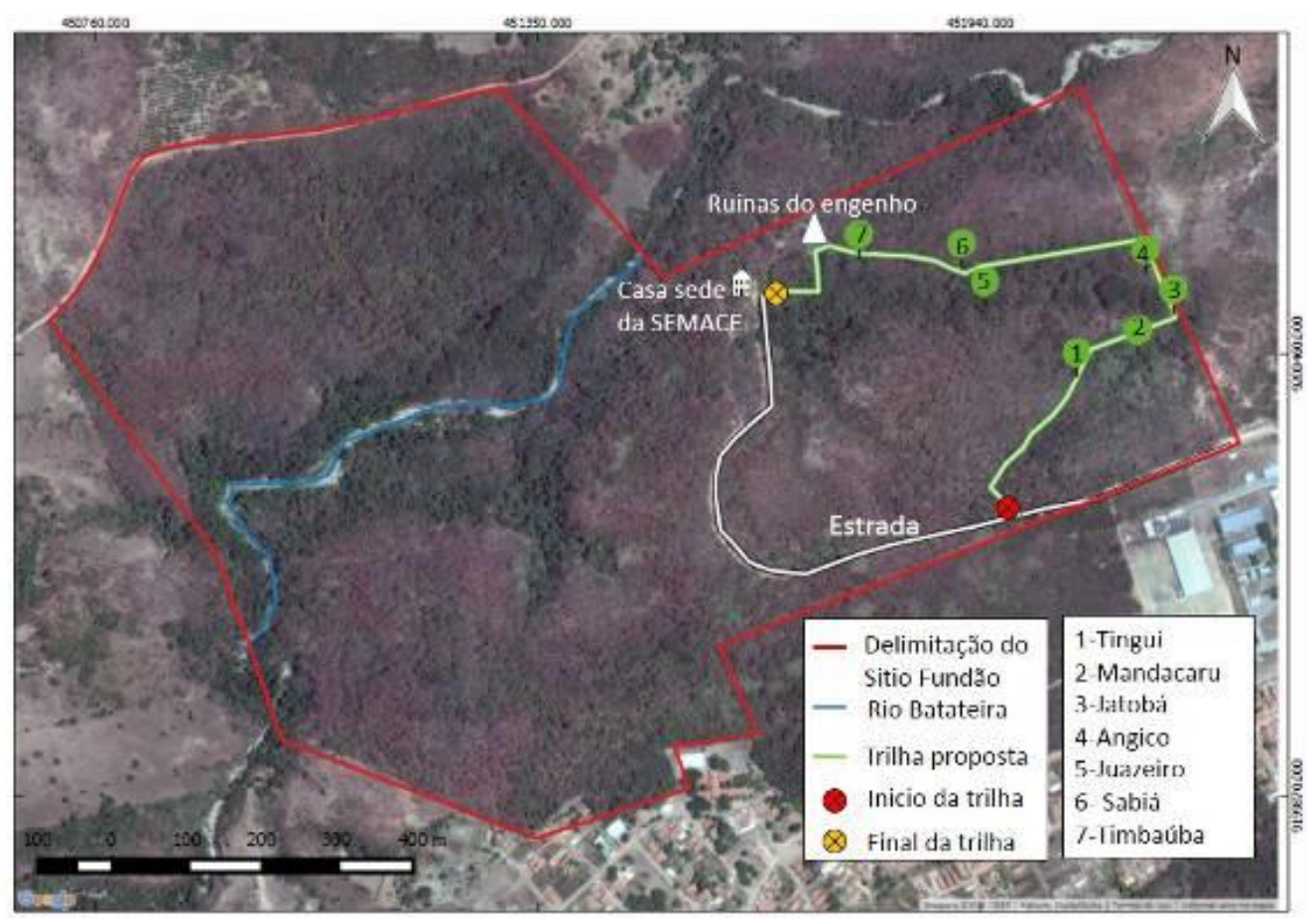

Figura 7: Mapa da trilha proposta. Fonte: FERNANDES, 2016. No prelo.

Revbea, São Paulo, V. 12, № 4: 207-218, 2017. 
Posteriormente, amostras das espécies identificadas e georreferenciadas devem ser coletadas, herborizadas e depositas no Herbário Caririense Dárdano de Andrade Lima da Universidade Regional do Cariri, para devida identificação do seu nome científico.

Fernandes et al. (2016) frisaram a importância da realização de um criterioso inventário para correta sinalização e identificação dos elementos da biodiversidade e geodiversidade no Pares Sítio Fundão como já vem sendo feito no seu patrimônio histórico-cultural, a identificação de novas trilhas, servem como instrumento para disseminação da EA, colaborando assim para a conservação e preservação dos seus patrimônios natural e cultural encontradas no PARES.

Para Pellin et al. (2014), pretendendo-se consolidar o turismo em trilhas, devem ser implementadas medidas como instalação de setas, placas informativas e interpretativas, o que facilita o desenvolvimento de ações e práticas voltadas à Educação Ambiental.

Com a sinalização, está sendo estabelecido um percurso com ênfase na flora nativa da região, pronto para uso como ferramenta de Educação Ambiental, ou seja, uma trilha interpretativa. A Educação Ambiental e a Interpretação Ambiental andam de mãos dadas, pois ambas buscam a conscientização do ser humano perante a natureza, e as trilhas interpretativas são importantes ferramentas pata viabilização de tomada de consciência (PROJETO DOCES MATAS, 2002; COLMAN; VAN DAL; SILVA, 2016).

\section{Conclusão}

Considerando a significativa riqueza encontrada no interior do Pares Sítio Fundão, fazem-se necessárias medidas que venham assegurar a proteção e conservação de seu patrimônio natural, seja sua biodiversidade ou sua geodiversidade, quanto seu patrimônio histórico e cultural. Para tal, a Educação Ambiental é uma ferramenta imprescindível.

Portanto, a proposta de melhoria e sinalização da trilha secundária da UC, só vem a contribuir para tal, bem como servir de ferramenta para disseminar novas formas de Educação Ambiental nesta UC, ampliando e divulgando assim os recursos naturais, culturais e históricos, além de servir de vínculo para mudanças de comportamentos, hábitos e atitudes dos visitantes.

Para isso, com base nas informações levantadas nesse trabalho de pesquisa, na identificação das espécies da flora nativa e no georreferenciamento das mesmas, pode-se planejar a sinalização da trilha e a abordagem a ser desenvolvida, sobretudo, pelos monitores do parque.

Um desdobramento inicial foi feito em fevereiro de 2017, onde a proposta foi apresentada à gestão e ao Conselho Consultivo do PARES Sítio Fundão, que decidiram aplicar a proposta e já iniciaram o trabalho de sinalização da trilha. 


\section{Referências}

ARAÚJO, D.; FARIAS, M.E. Trabalhando a construção de um novo conhecimento através dos sentidos em trilhas ecológicas. In: II Simposio Sul Brasileiro de Educação Ambiental. Anais. Itajai: Unilivre, 2003.

CEARÁ. Governo do estado do Ceará. Geopark Araripe: histórias da Terra, do Meio Ambiente e da Cultura. Projeto Cidades do Ceará, Crato, 2012.

COLMAN, D.A L.; VAN DAL, P.C.; SILVA, R.A.R. A Trilha Interpretativa Como Atividade De Educação Ambiental: O Que Pensam Os Professores? Revista da Associação Brasileira de Ensino de Biologia, n. 9, 2016.

CORDEIRO, M.N.; MACEDO, F.E.; BASTOS, F.H. Potencial Geoturístico do Cariri Cearense: O caso do Geopark Araripe. Acta Geográfica, v. 9, n. 19, p. 146-163, 2015.

COSTA, M.M.S.; SILVA, E.B.; MENESES, L.F. Proposta de trilha ecológica como atrativo ecoturístico na área de proteção ambiental da Barra do rio MamanguapePB. Revista Turismo: estudos e práticas, v. 1, n. 2, 2013.

COSTA, N M.C.; COSTA, V.C. Educação Ambiental em Unidades de Conservação da Natureza. In: PEDRINI, A.G.; SAITO, C.H. (Org). Paradigmas metodológicos em Educação Ambiental. Petrópolis: Vozes, 2014.

DEGRANDI, S.M. e FIGUEIRÓ, A.S. Patrimônio Natural e Geoconservação: a geodiversidade do município gaúcho de Caçapava do Sul. Revista Brasileira de Ecoturismo, São Paulo, v.5, n.2, p.173-196, 2012.

DIAS, G. F. Educação Ambiental: princípios e práticas.São Paulo: Gaia, 2004.

FERNANDES, P. A. S.; MOURA-FÉ, M. M.; VIEIRA, R. S.; PINHEIRO, M. A. Educação Ambiental Aplicada No Parque Estadual Sítio Fundão (Crato-Ce). In: SEABRA, G. (Org.). Educação Ambiental \& Biogeografia. Ituiutaba: Barlavento, 2016. Vol. I. 2360p.

FERNANDES, P.A. S.; PINHEIRO, M. A.; VIEIRA, R. S.; MOURA-FÉ, M. M. Educação Ambiental Aplicada No Parque Estadual Sítio Fundão: propostas iniciais de aplicação. Anais da XIII Semana de Biologia, 2016. No prelo.

JUSTO, W.R.; RODRIGUES, C.P.B. Valoração econômica do Parque Ecológico Estadual do Sítio Fundão, Crato, CE. Revista de Política Agrícola, v. 23, n. 1, p. 4-17, 2014.

LIMA-GUIMARÃES, S.T. Trilhas Interpretativas e Vivências na Natureza: aspectos relacionados à percepção e interpretação da paisagem. Caderno de Geografia, v. 20, n. 34, 2010.

LOBO, H.A.S.; MOREIRA, J.C.; FONSECA FILHO, R.E. Geoturismo e Conservação do Patrimônio Natural em áreas cársticas brasileiras. In: SEMINÁRIO DA ASSOCIAÇÃO NACIONAL PESQUISA E PÓS-GRADUAÇÃO EM TURISMO, 9., 2012, São Paulo-SP. 2012. Anais do IX Seminário Da Associação Nacional Pesquisa E Pós-Graduação Em Turismo. São Paulo, 2012.

MACEDO, J. A.; PINHEIRO, D.R.C. O Geoparque Araripe e o seu impacto no desenvolvimento local: Barbalha, Brasil. Geografia Ensino \& Pesquisa, v. 18, n. 2, p. 145-162, 2014. 
MELO, G.P. Educação Ambiental para professores e outros agentes multiplicadores. João Pessoa: Superintendência do IBAMA na Paraíba, 2007.

MORAIS, A. C. A.; JORGE, A. L.; SILVA, M. A. P. Mata Ciliar do Rio Batateiras no Sítio Fundão, Crato - CE. In: Educação Ambiental pata a Sociedade Sustentável e Saúde Global. Volume II / Giovanni de Farias Seabra, Ivo Thadeu Lira Mendonça (org.) - João Pessoa: Ed.Universitária da UFPB, 2009.

MOREIRA, J.C. Geoturismo: uma abordagem histórico-conceitual. Turismo e Paisagens Cársticas, v. 3, n. 1, p. 5-10, 2010.

MOURA-FÉ, M.M. GeoPark Araripe e a geodiversidade do sul do Estado do Ceará, Brasil. Revista de Geociências do Nordeste. v. 2, n. 1, p.28-37, 2016.

MOURA-FÉ, M.M. Geoturismo: uma proposta de turismo sustentável e conservacionista para a Região Nordeste do Brasil. Sociedade \& Natureza, v. 27, n. 1, p. 53-66, Uberlândia-MG: 2015b.

MOURA-FÉ, M.M.; PINHEIRO, M.V.A.; JACÓ, D.M.; OLIVEIRA, B.A. Geoeducação: a Educação Ambiental aplicada na geoconservação. In: Educação Ambiental \& Biogeografia. 1 ed. Ituiutaba-SP: Barlavento, 2016, v. II, p. 829-842.

OLIVEIRA, J.C.S. Geoparques no Brasil: foco geográfico na solução dos desafios. Monografia (Bacharelado em Geografia) Universidade de Brasília, Brasília, 2014. $124 p$.

PELLIN, A.; CARVALHO, G.; REIS, J.C.; PELLIN, A. Gestão do Uso Público em Unidades de Conservação Urbanas: o Caso do Parque Estadual da Pedra Branca (RJ). Revista Brasileira de Ecoturismo, São Paulo, v.7, n.2, maio/jul 2014, pp.344-373.

PIETROCHINSKI, A.H.R.; SILVA, V.F. Proposta de Sinalização Turística das Trilhas do Parque Estadual do Guartelá. Monografia (Trabalho de Conclusão de Curso) - Faculdade de Telêmaco Borba. Telêmaco Borba, PR, 2008.

PINHEIRO, M.V.A.; MOURA-FÉ, M.M.; SOUZA, G.S.; ANTUNES, M.R.V. A Importância da Aplicação da Educação Ambiental no Parque das Timbaúbas (Juazeiro do Norte - CE). SEABRA, G. (Org.). Educação Ambiental \& Biogeografia. Ituiutaba: Barlavento, 2016. Vol. II. 2762p.

PROJETO DOCE MATAS / GRUPO TEMÁTICO DE INTERPRETAÇÃO AMBIENTAL. Manual de introdução à interpretação ambiental. Belo Horizonte, 2002.

SENA, M. A. Parque Estadual Sítio Fundão. In: Governo do Estado do Ceará. Geopark Araripe: Historias da Terra, do Meio Ambiente e da Cultura. Governo do Estado do Ceará/Secretaria das Cidades/Projeto Cidades do Ceará- Cariri Central. Crato, 2012. p. 110.

SILVEIRA, A.C., SILVA, A.C.; CABRAL, N.R.A.J.; SCHIAVETTI, A. Análise de efetividade de manejo do Geopark Araripe - Estado do Ceará. Geociências (São Paulo), v. 31, n. 1, p. 117-128, 2012. 